\title{
Design of Microstrip UWB Antenna for Wireless Application
}

\author{
Pratima Thorat \\ Dept.of E\&TC Engineering \\ Pimpri Chinchwad College of \\ Engineering and Research Pune, \\ Maharashtra, India \\ Pranjali Wagh \\ Dept.of E\&TC Engineering \\ Pimpri Chinchwad College of \\ Engineering and Research Pune, \\ Maharashtra, India
}

\author{
Pratik Chandgude \\ Dept.of E\&TC Engineering \\ Pimpri Chinchwad College of \\ Engineering and Research Pune, \\ Maharashtra, India \\ Prof Rahul Prabat \\ Dept.of E\&TC Engineering \\ Pimpri Chinchwad College of \\ Engineering and Research Pune, \\ Maharashtra, India
}

\begin{abstract}
A compact rectangular microstrip antenna for Ultra Wide Band application is designed. The antenna with dimension $40 \mathrm{~mm} \times 35 \mathrm{~mm}(\mathrm{~L} \times \mathrm{W})$ is fabricated on FR-4 epoxy dielectric with relative permittivity of 4.4 and substrate height of $1.6 \mathrm{~mm}$ is designed and analyzed with different parameter like vswr, gain , return loss, bandwidth etc. The design antenna has the capability of operating between $3.1 \mathrm{GHz}$ to $10.6 \mathrm{GHz}$. Special configuration of patch antenna with slotted partial ground was designed and optimized using CADFEKO software.
\end{abstract}

\section{Keywords-Microstrip, UWB, Patch, Results}

\section{INTRODUCTION}

Wireless Communication has grown exponentially through the past few decades. It can communicate without any restriction on distance. The antenna is an essential part in the different communication systems to transmit and receive signals. The transmitting antenna is defined as a transducer that converts the generated electrical energy to electromagnetic wave radiated in space around the antenna, while the receiving antenna is also a transducer that converts the incoming electromagnetic waves from the surrounding space into an electrical energy and deliver it to the system components. Antennas can be considered as resonant devices since they work efficiently over a certain limited range of frequency band [1]. The advantages of the UWB technology are high data rate, less interference, secure, low cost and low complexity. The disadvantage of this technology is the need for accurate time synchronization at the receiver side since the pulse duration in time domain is fraction of nanosecond. It is used in different applications such as radar, imaging in medicine and military communication [3]. There are many different patch shapes such as the rectangular, circular, elliptic, circular ring, triangular and hexagonal. There are various techniques for feeding the antenna such as micro strip line feed, coaxial probed feed, aperture-coupled and electromagnetically coupled [4]. Wireless communication systems need high data rate which is achieved by increasing the available bandwidth. In 2002, FCC approved the UWB technology in the frequency range of $3.1-10.6 \mathrm{GHz}$ with maximum radiated power $41.3 \mathrm{dBm} / \mathrm{MHz}$ and data rate between 110-200 Mbps within 10 m distance (FCC, 2002) [5].

\section{DESIGN, ANALYSIS AND OPTIMIZATION}

The proposed rectangular microstrip patch antenna, shown in Fig. 1 is built on FR4 substrate with $\varepsilon r=4.4$ and $\tan \delta=0.02$. The antenna dimensions (in $\mathrm{mm}$ ) are: the substrate has Wsub $=35 \mathrm{~mm}, L s u b=40 \mathrm{~mm}$ and $\mathrm{h}=1.6 \mathrm{~mm}$, the patch of $\mathrm{W}=15$, $\mathrm{L}=16$, the feed has width $\mathrm{W}=3 \mathrm{~mm}$ and length $=12 \mathrm{~mm}$ the first patch cut has $W 1=10 \mathrm{~mm}, L 1=10 \mathrm{~mm}$ the partial ground plane has width $W g=35 \mathrm{~mm}$ and length $L g=11.5 \mathrm{~mm}$.

To the UWB antenna to designing the frequency is to from operating range $3.1 \mathrm{GHz}$ to $10.6 \mathrm{GHz}$ is the designing frequency, and the lower band edge frequency is $3.1 \mathrm{GHz}$ there assuming the FR4 substrate is $3 \mathrm{~mm}$ is using and calculating the wavelength of antenna is the formula we using Wavelength $(\pi)=\frac{C 0}{F * \sqrt{\epsilon r}} * 1000$ formula is used and assuming the $\in r=4.4$ and is $1000 \mathrm{~mm}$ will multiplying in the wavelength also the calculating the patch is width formula is Width $(w)=\frac{\lambda}{4}$ and Length $(l)=\frac{C}{4 f} * \sqrt{\frac{2}{\epsilon r+1}}$ is this using the formula to calculating patch and calculating the feed line is formula are $\mathrm{L}=$ less than $5 \%$ of patch length is these are the formula is using to design the UWB antenna of the range of $3.1 \mathrm{GHz}$ to $10.6 \mathrm{GHz}$. below table are the showing the measurement of the antenna we using for this above form

TABLE I. MEASUREMENT

\begin{tabular}{|c|c|c|}
\hline Sr. No & Symbols & Size in $\mathrm{mm}$ \\
\hline 1 & Wsub & 35 \\
\hline 2 & Lsub & 40 \\
\hline 3 & Wpatch & 15 \\
\hline 4 & Lpatch & 3 \\
\hline 5 & Wfeed & 12 \\
\hline 6 & Lfeed & 35 \\
\hline 7 & Wgnd & 11.5 \\
\hline 8 & Lgnd & 10 \\
\hline 9 & Wpc1 & 10 \\
\hline 10 & Lpc1 & 4 \\
\hline 11 & Wgndslot & 4 \\
\hline 12 & Lgndslot & 11.5 \\
\hline 13 & Wgndsidecut & \\
\hline 14 & Lgndsidecut & \\
\hline
\end{tabular}

Fig. 1. All Measurement of Antenna 


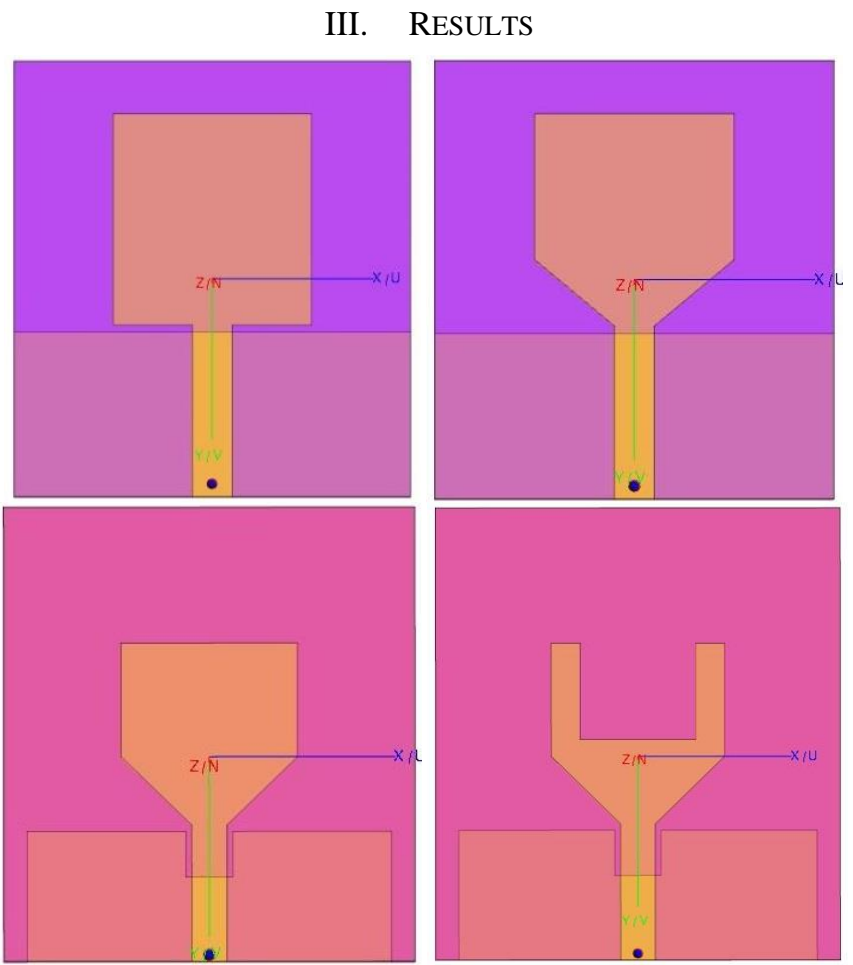

Fig. 2. Basic to final antenna process

In this the above Fig 2 is shows that the basic antenna at the first is simple then the changing the shape of the patch and cutting patch and the ground plan of DGS technique is using this cutting the patch is shown in above fig in and the next step will cut the DGS ground plane and is DGS of ground plane is results will be getting but the feed size cutting the gnd side square cutting and getting result below $-10 \mathrm{db}$ and the patch is cutting by different shapes will using this patch and getting different results where is step by step is cutting the patch where in results will current is not present in portion of patch will cutting the patch and DGS of gnd plane where the current is not present in that portion will cutting and the getting the where we required the signal in below $10 \mathrm{db}$ is the Signal will radiating that will design the UWB microstrip patch antenna. Where the results are getting in the different results and this results will showing in the below fig 3 and this are we cutting the patch of antenna in different way hence will be the getting required results to the UWB antenna.

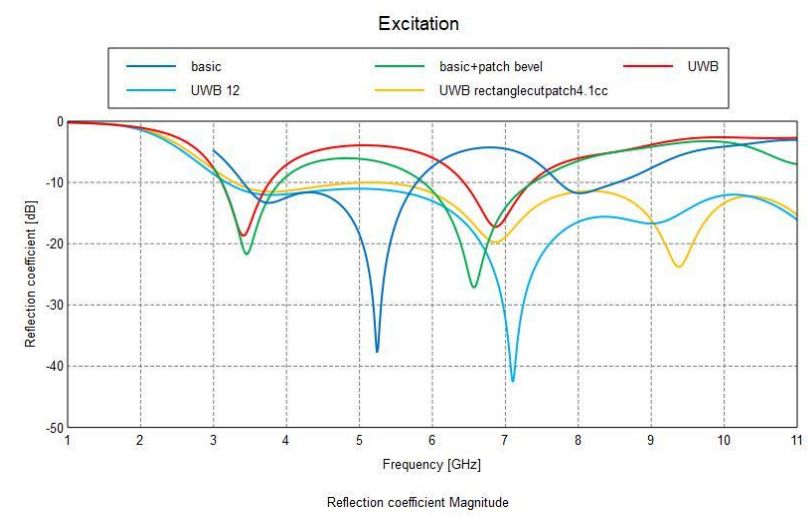

Fig. 3. Basic to final antenna reflection coefficent
The above fig is shows that the all antenna reflection coefficient result, and the is from first basic antenna to final antenna of the results of reflection coefficient is this show in the graph is are getting in below $-10 \mathrm{db}$ is the getting the results of perfect antenna reflection coefficient is getting is all the antenna reflection coefficient is shown and band is $3.1 \mathrm{GHz}$ to $10.6 \mathrm{GHz}$ is getting in below $-10 \mathrm{db}$ is the antenna will perform well and radiating the signal which is design for the ultra wide band microstrip patch antenna is getting .

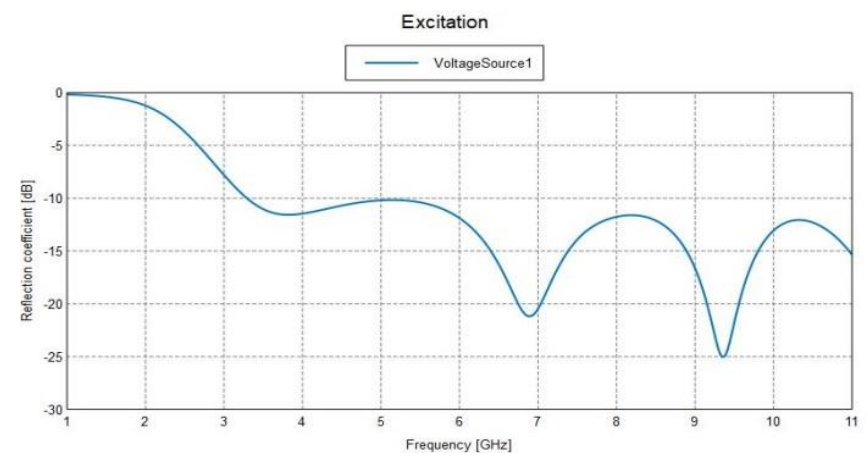

Fig. 4. Final antenna reflection coefficient

In the above reflection coefficient is the shown in the fig 4 is the final antenna result of the reflection coefficient, this result is shown the band of the ultra wide band is range of $3.1 \mathrm{GHz}$ to $10.6 \mathrm{GHz}$ is getting in the below $-10 \mathrm{db}$ and is required in the form is this graph is shown. And this above graph of this showing the results of the in $-10 \mathrm{db}$ where the accurate signal is transmitting range is $3.1 \mathrm{GHz}$ to $10.6 \mathrm{GHz}$ but the here will good range and transmitting range is $3.4 \mathrm{GHz}$ to the $10.2 \mathrm{GHz}$ is getting the range in this graph of UWB. There is the reflection coefficient of the UWB antenna of the results is shown in fig 3 is all the results of step by step cutting patch and getting the different results but the in fig 4 is shows that the band of the ultra wide band is range of $3.1 \mathrm{GHz}$ to $10.6 \mathrm{GHz}$ is getting in the below $-10 \mathrm{db}$ and is required in the form is this graph is shown and this will the results of graph of ultra wide band antenna of getting band.
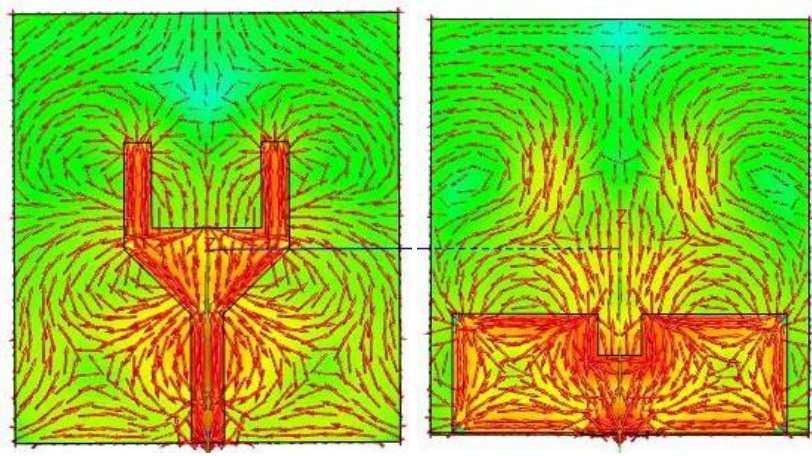

Fig. 5. Current flow

The above fig 5 is shows the current flow or current direction in the antenna which is working the antenna is range is $3.1 \mathrm{GHz}$ to $10.6 \mathrm{GHz}$ is operating range this rage is the current is required where the current is more in the antenna then is radiating the signal in give range, where the current is not present on the patch of antenna and ground plane those part 
or portion will be cutting because of good current flow and good radiating signal is shown above fig 5 .
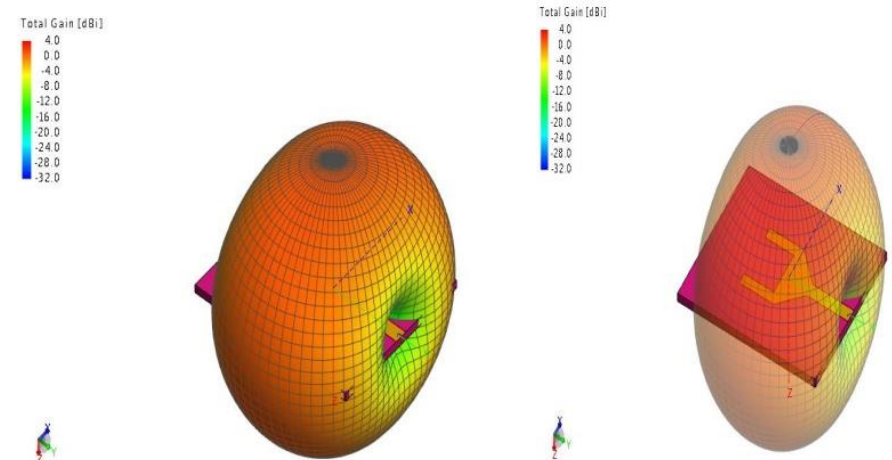

Fig. 6. 3D Radiation Pattern

This above 3D pattern fig 6 is shows the radiating patternof the current surrounding to the antenna of range is or current pattern is not in negative because the in antennacurrent is not radiating pattern in negative current that waythe current is required in positive is this hole antenna of the current is shown in $3 \mathrm{D}$ radiation pattern .
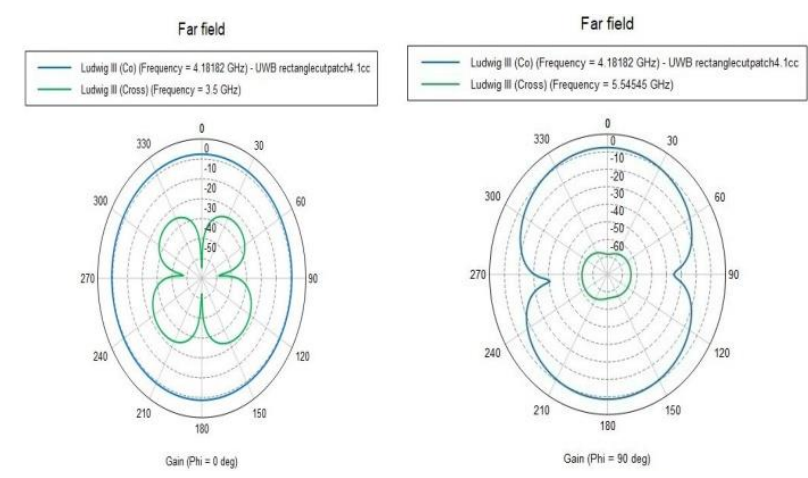

Fig. 7. Radiation Pattern

The above fig 7 is shows the radiation pattern of the designing of antenna of UWB micro strip antenna of the rage is $3.1 \mathrm{GHz}$ to $10.6 \mathrm{GHz}$ is operating range is this range antenna radiation pattern are shown in fig 7 . And the above fig is the two types are the omnidirectional and bidirectional is this type is showing in the above these results are the radiating signal of $3.1 \mathrm{GHz}$ to $10.6 \mathrm{GHz}$ is the signal and this are the opting the results is showing in the shapes of the omidiraction and the second one is bidirectional is this are results.

\section{CONCLUSION}

In this paper, Thus we obtained the results of the antenna is reflection coefficient band is getting $3.1 \mathrm{GHz}$ to $10.6 \mathrm{GHz}$, the gain of the pattern is $4 \mathrm{dbi}$ and the vswr of voltage standing wave ratio is obtain and the radiation pattern is of the frequency $3.1 \mathrm{GHz}$ to $10.6 \mathrm{GHz}$ there is getting the pattern . we proposed an UWB antenna which can support large bandwidth excited by a time domain pulse base signal to ensure the UWB signal is transmitted and received electively. By variation on the size of the ground patch at bottom layer, the optimization on return loss has been realized and the potential as the key parameter on return loss improvement has been demonstrated.

\section{REFERENCES}

[1] C .Balanis, "Antenna Theory, Analysis and Design" Second edition, John Wiley and sons, New York, 1997.

[2] UWB Theory and Application Edited by Ian oppemann, Jari Iinatti All of CWC, Univercity of Oula, finland

[3] Seok H. Choi, K. Park, Sun K. Kim, and Jae Y. Park, 4 Augus 2003: A new ultra wide band antenna for UWB application, Department of Radio Wave, Engineering Hanbat National University.

[4] "CAD-FEKO Simulation software, Version 6.3 User manual".

[5] NEWS Federal Communication Commission High-frequency releases 2002.

[6] Ren, W., J. Y. Deng, and K. S. Chen, "Compact PCB monopole antenna for UWB applications," Journal of Electromagnetic Waves and application Vol. 21, No.10, 1411-1420, 2007.

[7] International Journal of Engineering Technology and Advance engineering Website: www.ijetae.com (ISSN 2250-2459. ISO 9001: 2008 Certified Journal. Volume 4, Issue 9, September 2014)

[8] Imaging system. The second class of imaging systems those that operate with a $-10 \mathrm{~dB}$ bandwidth between $3.1 \mathrm{GHz}$ to $10.6 \mathrm{GHz} .109$ Emission levels from this category.

[9] H.G Schantz, "Introduction to ultra widwband antenna," IEEE Conference on Ultra Wideband System and Technologies, pp. 1-9 2003.

[10] G. M. Galvan-Tejada, M. A. Peyrot-Solis, and H. J.Aguilar, Ultra Wideband Antennas: Design, Methodo- Logies, and Performance Taylor \& Francis Group, 2017.

[11] K. Kikuta and A. Hirose, "Dispersion characteristics of ultra wideband antenna and their radiation patterns" In 2013 Internationa Symposium on Electromagnetic Theory, pp. 462-465 Hiroshima, 2013.

[12] D. Valderas, J. I. Sancho, D. Puente, C. Ling, and X.Chen, ultra wide band antennas: Design and Applicatio Imperial College Press London, UK, 2011.

[13] R. Garg, P. Bhartia, I. J. Bahl, and A. Ittipiboon, Micro-Strip Antenna Design Handbook, Artech House, 2001. 